\title{
Analisis Tingkat Kepuasan Pemustaka Terhadap Kinerja Pustakawan di Perpustakaan Daerah Kabupaten Sukabumi
}

\author{
${ }^{1}$ Neni Apriyani, ${ }^{2}$ Laksmi Dewi Ossira, ${ }^{3}$ Dini Suhardini \\ ${ }^{123}$ Universitas Pendidikan Indonesia \\ ${ }^{1}$ E-mail: neniapriyani@upi.edu \\ 2E-mail: laksmi@upi.edu \\ 3E-mail: dini_suhardini@upi.edu
}

\begin{abstract}
User service is an important element in the library. Libraries should provide the best services to the users or what is often called as excellent services. The excellent service really needs to be supported by the high performance of the librarian. So the users can feel satisfaction from the service thet get. This study aims to determine the level of the user's satisfaction to the librarian's performance in Perpustakaan Daerah Kabupaten Sukabumi and whether users have experienced unfavourable treatment due to the librarian's attitude. The method used in this research is quantitative survey research. The data was collected was through filling out the google form questionnaire. The sample of this research is 40 users who are a registered users in Perpustakaan Daerah Kabupaten Sukabumi. The result showed that the average score of user's satisfaction was 3.48 which mean that the users were satisfied with the librarian's performance. $70 \%$ of respondent stated that the librarian had worked professionally and $30 \%$ of respondent stated that they have experienced inappropriate treatment from the librarian in the form of unfriendly, indifferent, and slow in providing service.
\end{abstract}

Keyword: Excellent Service, User's Satisfaction, Librarian Performance.

\begin{abstract}
Abstrak
Pelayanan pemustaka merupakan salah satu unsur yang penting di perpustakaan. Perpustakaan harus bisa menyediakan pelayanan yang terbaik kepada pemustaka, atau yang biasa disebut dengan pelayanan prima. Pelayanan prima ini tentu perlu ditunjang dengan kinerja yang baik dari pustakawan yang bertugas. Dengan begitu, pemustaka bisa merasakan kepuasan dari layanan yang mereka dapatkan. Tujuan penelitian ini adalah untuk mengetahui tingkat kepuasan pemustaka atas kinerja pustakawan di Perpustakaan Daerah Kabupaten Sukabumi dan apakah mereka pernah mendapat perlakuan yang kurang berkenan dikarenakan oleh sikap pustakawan. Metode yang digunakan dalam penelitian ini adalah metode
\end{abstract}

Tik Ilmeu : Jurnal Ilmu Perpustakaan dan Informasi

IAIN Curup | p-issn: 2580-3654; e-issn:2580-3662

DOI: $10.29240 /$ tik.v5i2.2850 
survey yang bersifat kuantitatif. Sampel penelitian ini berjumlah 40 orang pemustaka Perpustakaan Daerah Kabupaten Sukabumi. Pengumpulan data dilakukan melalui pengisian google form. Hasil penelitian ini menunjukkan bahwa nilai kepuasan rata-rata pemustaka atas kinerja pustakawan di Perpustakaan Daerah Kabupaten Sukabumi adalah sebesar 3.48 yang artinya pemustaka merasa puas dengan kinerja pustakawan. Sebanyak $70 \%$ responden menyatakan bahwa pustakawan telah bekerja dengan professional dan 30\% menyatakan pernah mengalami perlakuan kurang menyenangkan dari pustakawan berupa sikap yang tidak ramah, bersikap cuek, dan lambat dalam memberikan pelayanan.

Kata Kunci: Pelayanan Prima, Kepuasan Pemustaka, Kinerja Pustakawan.

\section{A. PENDAHULUAN}

Perpustakaan merupakan salah satu lembaga yang menyediakan banyak informasi dalam berbagai bentuk, mulai dari bahan pustaka cetak sampai noncetak. Selain berfungsi sebagai penyedia informasi, perpustakaan juga memiliki fungsi lain, yaitu fungsi penyimpanan, fungsi penelitian, fungsi pendidikan, fungsi pelestarian, dan fungsi rekreasi/hiburan. Berbagai fungsi tersebut bisa saja berubah dikarenakan perpustakaan sendiri merupakan growing organism yang senantiasa berkembang seiring dengan perkembangan zaman.

Selain fungsinya yang beragam, perpustakaan juga terbagi menjadi beberapa jenis, diantaranya adalah perpustakaan umum termasuk di dalamnya perpustakaan daerah. Berdasarkan UU No. 43 Tahun 2007 tentang Perpustakaan, hadirnya perpustakaan umum daerah ini utamanya adalah untuk mendukung fungsi pendidikan dan pelestariaan yaitu berupa penyediaan fasilitas untuk mendukung program belajar masyarakat dan juga menyimpan serta mengabadikan berbagai budaya daerah. Perpustakaan umum daerah memiliki peran yang signifikan dalam kehidupan masyarakat sekitarnya sesuai dengan fungsinya sebagai sarana belajar, penyedia informasi, penelitian, dan sarana rekreasi. Dengan hadirnya perpustakaan daerah diharapkan bisa semakin meningkatkan budaya baca dan kualitas hidup masyarakat. Maka dari itu, seluruh pemustaka harus diberikan pelayanan yang maksimal oleh perpustakaan.

Berbicara mengenai layanan, tentunya tidak lepas dari yang namanya pustakawan. UU No. 43 Tahun 2007 Tentang Perpustakaan menyebutkan bahwa pustakawan adalah seseorang yang memiliki kompetensi yang diperoleh melalui pendidikan dan/atau pelatihan 
kepustakawanan serta mempunyai tugas dan tanggung jawab untuk melaksanakan pengelolaan dan pelayanan perpustakaan. Bisa dibilang, pusat dari kegiatan di perpustakaan adalah pelayanan kepada pemustaka. Maka dari itu, pustakawan sebagai pengelola perpustakaan memegang peranan yang sangat penting. Layanan diberikan kepada pemustaka agar mereka bisa memanfaatkan perpustakaan dengan sebaik-baiknya.

Di perpustakaan, ada yang disebut dengan pelayanan prima. Pelayanan prima berarti perpustakaan memberikan layanan kepada pemustaka melebihi dari prosedur yang telah ditetapkan dan berhasil melampaui harapan pelanggan, melalui pendekatan personal secara professional. Jadi, bisa dibilang perpustakaan harus selalu berupaya memberikan pelayanan yang semaksimal mungkin bagi pengguna agar harapan pengguna akan layanan bisa terpenuhi atau bahkan melampaui ekspektasi yang telah ditetapkan. Konsep dasar dari layanan prima sendiri terdiri dari tiga hal yaitu konsep sikap atau tingkah laku (attitude), konsep perhatian atau kepedulian (attention), serta konsep tindakan atau aksi (action). Tentunya, pemberian layanan tersebut tidak lepas dari campur tangan pustakawan sebagai pihak yang berperan melayani pemustaka. Untuk memberikan pelayanan yang prima tentunya dibutuhkan pustakawan berkualitas yang memilki kinerja yang baik.

Kinerja pustakawan akan sangat berpengaruh sekali terhadap pelayanan yang diberikan. Apabila pustakawan bisa memberikan pelayanan yang terbaik, maka hal ini akan memberikan citra yang positif bagi pustakawan dan perpustakaan. Dengan pelayanan terbaik pula, kemungkinan kebutuhan informasi pemustaka terpenuhi akan semakin besar. Dengan terpenuhinya kebutuhan pemustaka, hal itu akan memberikan kepuasan tersendiri dan bisa membuat mereka untuk datang kembali ke perpustakaan.

Penelitian yang terkait dengan topik ini dilakukan oleh Puspa (2017) yang berjudul "Analisis Kepuasan Pemustaka Terhadap Pelayanan Perpustakaan Pusat Penelitian dan Pengembangan Perikanan Budidaya". Penelitian tersebut meneliti tentang kepuasan pengguna terhadap berbagai aspek perpustakaan seperti koleksi, layanan, pustakawan, dan sarana pra sarana yang disediakan Puslitbangkan Budidaya. Hasilnya menunjukkan bahwa responden cukup puas dengan koleksi yang tersedia; responden cukup puas dengan sistem layanan yang disediakan; reponden merasa cukup puas dengan kinerja pustakawan; serta responden cukup puas dengan sarana dan prasarana yang tersedia. 
Penelitian lainnya dilakukan oleh Fahmi (2013) berjudul "Kajian Pengukuran Tingkat Kepuasan Pemustaka Terhadap Layanan Perpustakaan dan Informasi di Bidang Layanan Koleksi Umum Perpustakaan Nasional RI". Hasil penelitian tersebut menyatakan bahwa sebanyak 70,54\% responden merasa puas dengan koleksi di bagian layanan umum; 74,75\% responden merasa puas dengan layanan yang dsediakan bagian layanan umum; 76,88\% responden merasa puas dengan kinerja pustakawan di bagian layanan umum, dan 64,22 responden merasa puas dengan sarana dan pra sarana yang disediakan.

Perbedaan kedua penelitian di atas dengan penelitian ini adalah penulis memfokuskan terhadap ruang lingkup yang lebih spesifik, yaitu pada kinerja pustakawan dalam melakukan pelayanan. Tujuan penelitian ini adalah untuk mengetahui tingkat kepuasan pemustaka atas kinerja pustakawan di Perpustakaan Daerah Kabupaten Sukabumi dan apakah mereka pernah mengalami tindakan yang kurang berkenan disebabkan oleh sikap pustakawan.

Metode penelitian yang digunakan adalah metode survey yang bersifat kuantitatif dan pengumpulan datanya dilakukan melalui kuesioner. Populasi dalam penelitian ini merupakan pemustaka di Perpustakaan Daerah Kabupaten Sukabumi, tetapi karena jumlahnya yang banyak maka diambil sampel dari populasi tersebut. Metode probability sampling dengan teknik simple random sampling digunakan untuk mengambil sampel penelitian. Jumlah sampelnya yaitu sebanyak 40 orang pemustaka yang terdaftar sebagai angggota di Perpustakaan Daerah Kabupaten Sukabumi. Penelitian ini menggunakan instrumen berupa kuesioner yang berbentuk google form.

Pengukuran data dalam penelitian ini menggunakan skala likert. Skala likert merupakan skala yang digunakan untuk mengukur persepsi, sikap, atau pendapat seseorang atau kelompok mengenai sebuah peristiwa (Pranatawijaya et al. 2019). Skala likert menggunakan lima titik respon dalam penerapannya. Seiring berkembangnya ilmu pengetahuan, beberapa peneliti juga mengembangkan skala likert menjadi 5, 7, bahkan 11 titik. Pada penelitian ini ada lima titik yang digunakan. Pilihan jawaban yang diberikan kepada responden yaitu:
(1) $=$ STP $\quad$ : Sangat Tidak Puas
(2) $=$ TP $\quad$ : Tidak Puas
(3) $=$ CP $\quad$ : Cukup Puas
(4) $=\mathrm{P} \quad$ : Puas
(5) $=$ SP $\quad$ : Sangat Puas 
Sementara itu, untuk mengukur tingkat kepuasan pengguna dalam penelitian ini, maka digunakan skala penilaian sebagai berikut:

Tabel 1. Tingkat kepuasan pengguna

\begin{tabular}{cc}
\hline Skala & Kategori \\
\hline $1.00-1.80$ & Sangat Tidak Puas \\
$1.81-2.61$ & Tidak Puas \\
$2.62-3.42$ & Cukup puas \\
$3.43-4.23$ & Puas \\
$4.24-5.04$ & Sangat Puas \\
\hline
\end{tabular}

\section{B. HASIL DAN PEMBAHASAN}

\section{Kepuasan Pemustaka}

Kepuasan adalah perasaan yang dirasakan seseorang terkait barang atau jasa yang ia dapatkan setelah membandingkan hal tersebut dengan apa yang diharapkan. Zeithman \& Bitmar (dalam Tiemo and Ateboh, 2016) mendefinisikan kepuasan sebagai kondisi dimana pengguna menyatakan bahwa jasa atau produk yang mereka gunakan sesuai dengan kebutuhan atau harapan yang dimiliki. Apabila produk atau jasa yang digunakan sesuai dengan ekspektasi, maka bisa dikatakan pengguna merasa puas dengan produk atau jasa tersebut.

Pemustaka merupakan pengguna (user) yang memanfaatkan atau memakai sarana, fasilitas dan seluruh layanan yang disediakan perpustakaan baik secara perseorangan, kelompok orang, masyarakat, ataupun lembaga. Perpustakaan melayani seluruh pemustakanya secara adil tanpa membedakan gender, agama, umur, etnis, ideologi, dan pandangan politik. Terutama perpustakaan umum boleh dimanfaatkan oleh seluruh masyarakat sekitar. Sedangkan untuk perpustakaan khusus atau perpustakaan di bawah naungan lembaga tertentu, pemustakanya ditentukan sesuai dengan kebijakan masing masing. Namun yang pasti perpustakaan harus berusaha semaksimal mungkin agar bisa menyediakan informasi sesuai yang dibutuhkan oleh pemustakanya.

Menurut Joy and Idowu (2014) kepuasan pemustaka merupakan perasaan yang dimiliki pemustaka setelah merasakan pelayanan dan menggunakan berbagai sumber daya yang tersedia di perpustakaan serta 
keinginan mereka untuk kembali lagi ke perpustakaan apabila mereka membutuhkan informasi lagi.

Kepuasan pemustaka merupakan perasaan kecewa atau senang yang dialami pemustaka selepas mereka membanding antara hasil yang didapat atau diterima dengan apa yang mereka harapkan. Dalam hal perpustakaan, berarti menyangkut segala layanan dan sumber daya yang bisa dimanfaatkan oleh pengguna. Pengguna bisa menentukan kepuasan mereka setelah menggunakan layanan dan sumber daya yang tersedia di perpustakaan. Apabila perpustakaan menyediakan layanan yang tidak sesuai harapan maka pemustaka akan merasakan ketidakpuasan; ketika layanan yang disediakan sepadan dengan keinginan pemustaka maka mereka akan merasakan kepuasan; serta apabila layanan yang disediakan melebihi ekspektasi pemustaka maka pemustaka akan merasa sangat puas.

Kepuasan pemustaka sangat penting untuk diketahui oleh perpustakaan. Kepuasan atas layanan perpustakaan yang dirasakan oleh pemustaka akan memberikan dampak konstruktif bagi perpustakaan itu sendiri. Pemustaka tersebut berpeluang besar untuk kembali lagi ke perpustakaan untuk memanfaatkan segala sumber daya yang ada ketika mereka membutuhkan informasi. Pelayanan yang memuaskan juga akan meningkatkan citra baik pustakawan dan perpustakaan itu sendiri. Seperti yang dikemukakan oleh Tiemo \& Ateboh (2016) bahwa pemustaka yang merasa puas dengan layanan dan sumber daya yang tersedia di perpustakaan akan memberitahukan hal tersebut kepada pemustaka lainnya. Hal tersebut juga nantinya bisa menarik lebih banyak pemustaka untuk berkunjung ke perpustakaan.

\section{Kinerja Pustakawan}

Ketika berbicara mengenai kinerja maka berkaitan pula dengan kompetensi. Menurut Siregar (2015) kompetensi merupakan kapasitas seseorang dalam melakukan pekerjaan atau tugas yang berlandaskan tiga hal yaitu pengetahuan atau keilmuan (knowledge), keterampilan atau keahlian (skill), dan sikap atau tingkah laku (attitude). Terdapat dua jenis kompetensi yaitu soft competency yang berhubungan dengan keterampilan untuk mengatur dan mengorganisasikan pekerjaan serta cara berinteraksi dengan orang lain; dan hard competency yang berhubungan dengan kapasitas fungsional atau teknis untuk melakukan suatu pekerjaan. Kompetensi pustakawan merupakan gabungan dari berbagai hal seperti pengetahuan, keterampilan, sikap, karakteristik dan nilai perilaku yang dimiliki oleh 
pustakawan dalam melakukan pekerjaannya sehingga bisa mencapai kinerja yang unggul (Sari and Permana 2012)

Menurut Wahyuningsih (2019) kinerja merupakan keberhasilan yang diraih seseorang dalam menyelesaikan pekerjaannya yang berkaitan dengan kualitas, kuantitas, mampu bekerja sama dan memahami tugasnya, disiplin, mampu mengembangkan potensi yang dimiliki, serta didukung oleh semangat kerja yang tinggi. Menurut Hasibuan (dalam Nurcahyawati, 2017) kinerja merupakan hasil kerja yang didapatkan seseorang tatkala melakukan pekerjaannya yang didasari oleh keahlian, pengalaman, intensitas dan waktu. Kinerja merupakan gabungan dari kemampuan, minat, keterampilan, penerimaan atas peran, tugas dan tingkat motivasi. Semakin tinggi faktor faktor tersebut, kinerja yang dihasilkan juga akan semakin besar.

Pustakawan merupakan seseorang yang memiliki tugas mengelola perpustakaan dan melayani pemustaka sesuai dengan ketetapan yang dimiliki oleh perpustakaan. Kinerja pustakawan merupakan hasil kerja yang diperoleh oleh pustakawan selama menjalankan tugas serta tanggung jawabnya senada dengan ketentuan yang dimiliki oleh perpustakaan tempatnya bekerja. Hal ini mencakup sejauhmana pustakawan mampu mengelola perpustakaan dan melayani pemustaka yang berkunjung ke perpustakaan.

Kompetensi berhubungan erat dengan kinerja. Kompetensi merupakan campuran berbagai hal mulai dari pengetahuan, keterampilan, sampai sikap yang diperlukan seseorang untuk melaksanakan suatu pekerjaan. Sementara kinerja adalah hasil kerja actual seseorang, yang dimana untuk melakukan pekerjaan tersebut tentunya dibutuhkan sejumlah kompetensi yang sesuai dengan pekerjaan yang dilakoni. Oleh karenanya, kompetensi akan sangat berpengaruh terhadap kinerja seseorang. Adapun indikator kinerja merupakan skala atau karakteristik tertentu yang dipergunakan untuk mengukur tingkat keberhasilan kinerja. Pengukuran ini penting dilakukan untuk mengetahui apakah seseorang telah mencapai kinerja sesuai dengan yang diharapkan atau tidak.

\section{Perpustakaan Daerah Kabupaten Sukabumi}

Kantor Perpustakaan Daerah Kabupaten Sukabumi berlokasi di Jl. Raya Cisaat-Cigayung, Komplek Gelanggang Pemuda Cisaat, Sukabumi. Secara historis, Kantor Perpustakaan Daerah Kabupaten Sukabumi telah mengalami beberapa kali perubahan nama, yaitu:

1. Taman Pustaka Tingkat C (1973-1975);

2. Taman Pustaka Masyarakat Tingkat C (1975-1990); 
3. UPT Dinas Pada Dinas Pendidikan dan Kebudayaan Daerah Tingkat II Kabupaten Sukabumi (1990-1996);

4. Unit Pelaksana Daerah (1996-1998);

5. Kantor Perpustakaan Umum Daerah Tingkat II Sukabumi (1998-2000);

6. UPT Perpustakaan Umum di Bawah Badan Komunikasi dan Promosi Daerah Kabupaten Sukabumi (2000-2002);

7. Kantor Perpustakaan Umum Daerah Kabupaten Sukabumi (2002-2007);

8. Kantor Perpustakaan Daerah Kabupaten Sukabumi (2007-Sekarang).

Sama seperti tujuan perpustakaan pada umumnya, Perpustakaan Daerah Kabupaten Sukabumi juga berkomitmen untuk memberikan fasilitas dan layanan yang maksimal bagi masyarakat. Masyarakat bisa memanfaatkan perpustakaan sebagai pusat pendidikan, informasi bahkan rekreasi. Untuk mewujudkan pelayanan yang maksimal, tentunya tidak lepas dari peran pustakawan di belakangnya. Pustakawan perlu bekerja dengan maksimal agar pemustaka mampu merasakan kepuasan atas layanan yang diberikan.

\section{Tingkat Kepuasan Pemustaka Terhadap Kinerja Pustakawan}

Ada beberapa indikator yang digunakan untuk mengukur tingkat kinerja pustakawan dalam penelitian ini, dimana hasilnya yaitu sebagai berikut:

Tabel 2. Jawaban responden terhadap kinerja pustakawan

\begin{tabular}{|c|c|c|c|c|c|c|c|c|c|c|c|}
\hline \multirow{2}{*}{ Indikator } & \multicolumn{5}{|c|}{ Jawaban responden } & \multicolumn{5}{|c|}{$\%$} & \multirow{2}{*}{ Mean } \\
\hline & STP & TP & $\mathrm{CP}$ & $\mathrm{P}$ & SP & STP & TP & $\mathrm{CP}$ & $\mathrm{P}$ & SP & \\
\hline $\begin{array}{l}\text { Pustakawan } \\
\text { mampu } \\
\text { memahami } \\
\text { kebutuhan } \\
\text { pemustaka } \\
\text { dengan baik }\end{array}$ & 0 & 3 & 18 & 13 & 6 & $0 \%$ & $7,5 \%$ & $45 \%$ & $32,5 \%$ & $15 \%$ & 3,55 \\
\hline $\begin{array}{l}\text { Pustakawan } \\
\text { membantu } \\
\text { pemustaka } \\
\text { yang } \\
\text { mengalami } \\
\text { masalah } \\
\text { layanan }\end{array}$ & 0 & 5 & 18 & 12 & 5 & $0 \%$ & $12,5 \%$ & $45 \%$ & $12 \%$ & $5 \%$ & 3,42 \\
\hline $\begin{array}{l}\text { Pustakawan } \\
\text { melayani } \\
\text { pemustaka } \\
\text { dengan ramah } \\
\text { dan santun }\end{array}$ & 0 & 11 & 5 & 14 & 10 & $0 \%$ & $27,5 \%$ & $12,5 \%$ & $35 \%$ & $25 \%$ & 3,57 \\
\hline Pustakawan & 0 & 0 & 13 & 14 & 13 & $0 \%$ & $0 \%$ & $32,5 \%$ & $35 \%$ & 32,5 & 4,00 \\
\hline
\end{tabular}




\begin{tabular}{|c|c|c|c|c|c|c|c|c|c|c|c|}
\hline $\begin{array}{l}\text { Pustakawan } \\
\text { cepat tanggap } \\
\text { dalam } \\
\text { melakukan } \\
\text { pelayanan }\end{array}$ & 0 & 8 & 14 & 9 & 9 & $0 \%$ & $20,0 \%$ & $35 \%$ & $22,5 \%$ & $22,5 \%$ & 3,47 \\
\hline $\begin{array}{l}\text { Pustakawan } \\
\text { mampu } \\
\text { berkomunikasi } \\
\text { dengan baik }\end{array}$ & 0 & 2 & 19 & 9 & 10 & $0 \%$ & $5 \%$ & $47,5 \%$ & $22,5 \%$ & $25 \%$ & 3,67 \\
\hline $\begin{array}{l}\text { Pustakawan } \\
\text { menguasai } \\
\text { teknologi }\end{array}$ & 0 & 2 & 23 & 11 & 4 & $0 \%$ & $5 \%$ & 57,55 & $22,5 \%$ & $10 \%$ & 3,42 \\
\hline $\begin{array}{l}\text { Pustakawan } \\
\text { memberikan } \\
\text { bimbingan } \\
\text { untuk } \\
\text { melakukan } \\
\text { pencarian } \\
\text { informasi }\end{array}$ & 0 & 13 & 14 & 8 & 5 & $0 \%$ & $32,5 \%$ & $35 \%$ & $20 \%$ & $12,5 \%$ & 3,12 \\
\hline $\begin{array}{l}\text { Pustakawan } \\
\text { memberikan } \\
\text { informasi } \\
\text { dengan jelas } \\
\text { dan akurat }\end{array}$ & 0 & 7 & 21 & 6 & 6 & $0 \%$ & $17,5 \%$ & $52,5 \%$ & $15 \%$ & $15 \%$ & 3,27 \\
\hline $\begin{array}{l}\text { Pustakawan } \\
\text { terbuka } \\
\text { terhadap kritik } \\
\text { dan saran }\end{array}$ & 0 & 5 & 21 & 10 & 4 & $0 \%$ & $12,5 \%$ & 52,5 & $25 \%$ & $10 \%$ & 3,32 \\
\hline
\end{tabular}

1. Pustakawan mampu memahami kebutuhan pemustaka dengan baik Berdasarkan hasil penelitian, sebanyak $0 \%$ responden mengungkapkan sangat tidak puas, $7,5 \%$ tidak puas, $45 \%$ cukup puas, $32.5 \%$ puas, dan $15 \%$ sangat puas. Rata-rata nilai kepuasannya adalah sebesar 3.55 yang artinya pemustaka puas karena pustakawan mampu memahami kebutuhan informasi mereka dengan baik.

2. Pustakawan membantu pemustaka yang mengalami masalah layanan Berdasarkan hasil penelitian, sebanyak $0 \%$ responden mengungkapkan sangat tidak puas, $12.5 \%$ tidak puas, $45 \%$ cukup puas, $12 \%$ puas dan $5 \%$ sangat puas. Rata-rata nilai kepuasannya adalah sebesar 3.42 yang berarti pemustaka merasa cukup puas atas bantuan yang diberikan pustakawan ketika mereka mengalami kesulitan.

3. Pustakawan melayani pemustaka dengan ramah dan santun 
Berdasarkan hasil penelitian, sebanyak $0 \%$ responden menngungkapkan sangat tidak puas, $27.5 \%$ tidak puas, $12.5 \%$ cukup puas, $35 \%$ puas, dan $25 \%$ sangat puas. Rata-rata nilai kepuasannya adalah sebesar 3.57 yang artinya pemustaka merasa puas terhadap pustakawan karena bersikap ramah dan santun.

4. Pustakawan berpenampilan rapi dan sopan

Berdasarkan penelitian, sebanyak $0 \%$ responden mengungkapkan sangat tidak puas, $0 \%$ tidak puas, $32.5 \%$ cukup puas, $35 \%$ puas, dan $32.5 \%$ sangat puas. Rata-rata nilai kepuasannya adalah sebesar 4.00 yang artinya pemustaka merasa puas dengan penampilan pustakawan yang rapi dan sopan.

5. Pustakawan cepat tanggap dalam melakukan pelayanan

Berdasarkan hasil penelitian, sebanyak $0 \%$ mengungkapkan sangat tidak puas, $20 \%$ tidak puas, $35 \%$ cukup puas, $22.5 \%$ puas, dan $22.5 \%$ sangat puas. Rata-rata nilai kepuasannya adalah sebesar 3.47 yang artinya pemustaka merasa puas karena pustakawan cepat tanggap dalam melayani pemustaka.

6. Pustakawan mampu berkomunikasi dengan baik

Berdasarkan hasil penelitian, sebanyak $0 \%$ responden mengungkapkan sangat tidak puas, $5 \%$ tidak puas, $47.5 \%$ cukup puas, $22.5 \%$ puas, dan $25 \%$ sangat puas. Rata-rata nilai kepuasannya sebesar 3.67, artinya pemustaka merasa puas dengan kemampuan komunikasi yang dimiliki pustakawan.

7. Pustakawan menguasai teknologi

Berdasarkan penelitian, sebanyak $0 \%$ responden mengungkapkan sangat tidak puas, $5 \%$ tidak puas, $57.5 \%$ cukup puas, $27.5 \%$ puas, dan $10 \%$ sangat puas. Rata-rata nilai kepuasannya adalah sebesar 3.42 yang artinya pemustaka cukup puas dengan kemampuan pustakawan dalam menguasai teknologi.

8. Pustakawan memberikan bimbingan untuk melakukan pencarian informasi Berdasarkan penelitian, sebanyak $0 \%$ responden mengungkapkan sangat tidak puas, $32.5 \%$ tidak puas, $35 \%$ cukup puas, $20 \%$ puas, dan $12.5 \%$ puas. Rata-rata nilai kepuasannya adalah sebesar 3.12 yang berarti pemustaka merasa cukup puas atas bimbingan yang dilakukan oleh pustakawan dalam melakukan pencarian informasi.

9. Pustakawan memberikan informasi dengan jelas dan akurat Berdasarkan penelitian, sebanyak $0 \%$ responden mengungkapkan sangat tidak puas, $17.5 \%$ tidak puas, $52.5 \%$ cukup puas, $15 \%$ puas, dan $15 \%$ sangat puas. Rata-rata nilai kepuasannya adalah sebesar 3.27 yang artinya 
pemustaka merasa cukup puas karena pustakawan memberikan informasi dengan jelas dan akurat.

10. Pustakawan terbuka terhadap kritik dan saran

Berdasarkan penelitian, sebanyak $0 \%$ responden mengungkapkan sangat tidak puas, $12.5 \%$ tidak puas, $52.5 \%$ cukup puas, $25 \%$ puas, dan $10 \%$ sangat puas. Rata-rata nilai kepuasannya adalah sebesar 3.32 yang artinya pemustaka merasa cukup puas karena pustakawan terbuka dengan kritik dan saran yang disampaikan.

Meskipun secara keseluruhan responden menyatakan puas dengan kinerja pustakawan, mereka tetap menyatakan beberapa keluhan terkait dengan sikap tidak professional yang ditunjukkan oleh pustakawan selama melakukan pelayanan. Sebanyak 30\% responden menyatakan mereka pernah mendapat perlakuan yang kurang professional dari pustakawan, dimana pustakawan terkesan tidak ramah atau judes, bersikap cuek, serta agak lambat dalam membantu mengatasi masalah pemustaka. Responden menyatakan hal itu kemungkinan dikarenakan pemustaka yang berkunjung ke perpustakaan sangat ramai sehingga pustakawan harus membagi fokus dengan banyak hal dan merasa kelelahan yang berakibat pada pelayanan terhadap pemustaka lain menjadi kurang maksimal.

Sementara itu, $70 \%$ responden lainnya menyatakan mereka tidak pernah mendapat perlakuan yang terkesan tidak professional dari pustakawan yang bertugas. Mereka menyatakan bahwa pustakawan telah bekerja dengan maksimal dalam melaksanakan tugasnya. Hal ini berimbas pada responden yang merasa puas dengan kinerja yang ditunjukkan oleh pustakawan.

Secara keseluruhan, nilai kepuasan rata-rata yang ditunjukkan adalah sebesar 3.48. Hasil tersebut menunjukkan bahwa pemustaka merasa puas atas kinerja yang ditampilkan oleh pustakawan di Perpustakaan Daerah Kabupaten Sukabumi. Sebanyak $70 \%$ responden juga berpendapat pustakawan telah berkerja dengan maksimal dalam melaksanakan tugasnya. Senada dengan penelitian yang dilaksanakan oleh Nafidah (2015) bahwa kinerja pustakawan memiliki pengaruh terhadap tingkat kepuasan pemustaka. Semakin tinggi kinerja pustakawan maka kepuasan yang dirasakan pemustaka juga akan semakin tinggi.

\section{KESIMPULAN}


Berdasarkan temuan dari penelitian yang dilakukan, maka penulis menarik kesimpulan sebagai berikut:

1. Nilai kepuasan rata-rata yang ditunjukkan adalah sebesar 3.48 yang artinya pemustaka merasa puas dengan kinerja pustakawan di perpustakaan daerah kabupaten sukabumi.

2. Sebanyak $70 \%$ responden berpendapat bahwa pustakawan telah bekerja dengan professional. Sedangkan sebanyak 30\% lainnya menyatakan mereka pernah mendapat perlakuan yang tidak professional dari pustakawan dimana pustakawan bersikap tidak ramah, bersikap cuek, dan agak lambat dalam melakukan pelayanan.

\section{DAFTAR RUJUKAN}

Abdul, Ir, Rahman Saleh. (2008). "ISO 11620 : 2008.” 2008 (January 2013): $1-15$.

Budiaji, Weksi. (2013). "Skala Pengukuran Dan Jumlah Respon Skala Likert (The Measurement Scale and The Number of Responses in Likert Scale)." Ilmu Pertanian dan Perikanan 2(2):127-33.

Budiyanto, Agung, \& Ary Setiyadi. (2020). "Persepsi Pemustaka Terhadap Sikap Pustakawan di UPT Perpustakaan Universitas Semarang." 1(1):17.

Dinas Kearsipan dan Perpustakaan Kabupaten Sukabumi. (n.d.) "Profill". Retrieved May 20, 2021 (https://diarpus.sukabumi.go.id/profil/sejarah).

Fahmi. (2013). "Kajian Pengukuran Tingkat Kepuasan Pemustaka Terhadap Layanan." Media Pustakawan 20(3):46-55.

Gunartik, Gunartik, \& Nora Pitri Nainggolan. (2019). "Pengaruh Kualitas Pelayanan dan Fasilitas Terhadap Kepuasan Pengguna Perpustakaan (di Politeknik Negeri Batam).” Jurnal Akuntansi Barelang 3(2):29. doi: 10.33884/jab.v3i2.1250.

Harmoko, Sapto. (2017). "Analisis Tingkat Kepuasan Pemustaka Terhadap Kualitas Layanan di Perpustakaan Politeknik Kesehatan Kementerian Kesehatan Yogyakarta." JIPI (Jurnal Ilmu Perpustakaan Dan Informasi) Vol. 2 No. 2 Tahun 2017 ISSN (Online): 2528-021X 2(2):164-88.

Islamy, Muhammad. (2016). “Analisis Tingkat Kepuasan Pemustaka Tentang Kualitas Layanan Perpustakaan dengan Menggunakan Metode 
Libqual+tm : Studi Deskriptif di Perpustakaan Pusat Institut Teknologi Bandung." Edulib 1(75):1-11.

Joy, Ikenwe Iguehi \& Adegbilero-Iwari Idowu. (2014). "Utilization and User Satisfaction of Public Library Services in South-West, Nigeria in the 21 St Century: A Survey." International Journal of Library Science 2014(1):1-6. doi: 10.5923/j.library.20140301.01.

Nafidah, Nurul. (2015). "Pengaruh Kinerja Pustakawan Terhadap Kepuasan Pemustaka Pada Perpustakaan Universitas Indonesia." 1-119.

Nurcahyawati, Vivine. (n.d.). "Analisis Kepuasan Pengguna Layanan dengan Metode Service Quality Berbasis Web.”3(2018):1-11.

Pranatawijaya, Viktor Handrianus, Widiatry Widiatry, Ressa Priskila, \& Putu Bagus Adidyana Anugrah Putra. (2019). "Penerapan Skala Likert dan Skala Dikotomi Pada Kuesioner Online.” Jurnal Sains Dan Informatika 5(2):128-37. doi: 10.34128/jsi.v5i2.185.

Puspa, Erny. (2017). "Analisis Kepuasan Pemustaka Terhadap Pelayanan Perpustakaan Pusat Penelitian dan Pengembangan Perikanan Budidaya." Jurnal Pari 2(2):113. doi: 10.15578/jp.v2i2.3256.

Rani. (2017). "Kualitas Layanan Prima di Perpustakaan." -. Retrieved May 22, 2021 (https://dispusip.jakarta.go.id/dispusip/2017/04/14/kualitaslayanan-prima-di-

perpustakaan/\#: :text=pengertian\%2520pelayanan\%2520prima20\%25y aitu\%2520memberikan,tahun\%25202007\%252C\%2520tentang\%2520la yanan\%2520perpustakaan ).

Republik Indonesia. (2007). "Undang-Undang Nomor 43 Tahun 2007 Tentang Perpustakaan." UU No. 23 Th 2007 67(6):14-21

Sari, Diyah Kartika, \& Aan Permana. (2012). "Pengaruh Kompetensi Pustakawan Terhadap Kinerja Perpustakaan di UPT Perpustakan Universitas Negeri Semarang.” Jurnal Ilmu Perpustakaan 1(1):28-34.

Siregar, Muhammad Riandy Arsin. (2015). "Kompetensi yang Harus Dimiliki Seorang Pustakawan (Pengelola Perpustaakaan)." Jurnal Iqra' 09(02):211-22.

Tiemo, Pereware Aghwotu, \& Benedict Alaowei Ateboh. (2016). "Users' Satisfaction with Library Information Resources and Services: A Case Study College of Health Sciences Library Niger Delta University, 
Amassoma, Nigeria." Journal of Education and Practice 7(16):54-59.

Wahyuningsih, Pilih. (2019). "Hubungan Kinerja Pustakawan dengan Kepuasan Pengguna Studi Kasus Pada Perpustakaan SMK Negeri 1 Ngablak." UNILIB : Jurnal Perpustakaan 10(2):105-9. doi: 10.20885/unilib.vol10.iss2.art7.

Yanita, Fitriani, Aan Permana, \& Desy Ery Dani. (2013). "Persepsi Pemustaka Terhadap Kinerja Pustakawan: Studi Kasus Layanan Sirkulasi Perpustakaan Stikes Widya Husada Semarang." Jurnal Ilmu Perpustakaan 2(1):1-11.

Yunus. (2013). “Analisis Tingkat Kepuasan Pengguna Terhadap Layanan Perpustakaan di Badan Perpustakaan dan Kearsipan Provinsi Jawa Timur Tahun 2012.” Media Pustakawan 20(1):9-18.

Yusrawati. (2016). "Evaluasi Kinerja Pustakawan Perpustakaan Perguruan Tinggi Melalui Standar PAK dan ISO 11620-1998.” Libria 8(1):143-55. 